\title{
Surgical management of a rare circumflex coronary artery fistula draining into the coronary sinus
}

\author{
Jetsen A. Rodriguez ${ }^{a}$, Limael E. Rodriguez ${ }^{a, *}$, Manuel Santiago-Cummings ${ }^{b}$, Ernesto R. Soltero ${ }^{b}$ \\ a Department of Surgery, St. Luke's Memorial Hospital, Ponce Health Sciences University, Ponce, PR, USA \\ ${ }^{\mathrm{b}}$ Department of Cardiothoracic Surgery, Damas Hospital, Ponce Health Sciences University, Ponce, PR, USA
}

\section{A R T I C L E I N F O}

\section{Article history:}

Received 8 December 2016

Received in revised form 4 August 2017

Accepted 7 August 2017

Available online 8 August 2017

\section{Keywords:}

Coronary artery fistula

CAF

Left circumflex artery

Coronary sinus

Intracardiac shunting

\begin{abstract}
A B S T R A C T
Coronary artery fistula (CAF) is a rare anomalous connection between a coronary artery and a cardiac chamber or a major vessel. The majority arise from the right coronary artery and drain into the right heart structures. In this report, we present a rare case of a left circumflex coronary artery fistula draining into the coronary sinus managed successfully with surgical intervention.

(c) 2017 The Society of Cardiovascular Academy. Production and hosting by Elsevier B.V. This is an open access article under the CC BY-NC-ND license (http://creativecommons.org/licenses/by-nc-nd/4.0/).
\end{abstract}

\section{Introduction}

Coronary artery fistula (CAF) is defined as an abnormal connection between a coronary artery and a cardiac chamber or any of the great vessels. ${ }^{1}$ The majority of CAFs are congenital and not gender specific. In adults, coronary artery fistula (CAF) with pathologic intra-cardiac shunting is very uncommon $(<0.002 \%$ of the general population), as most are detected and repaired during childhood. ${ }^{1-4}$ The left circumflex coronary artery (LCX) is rarely involved (up to $17 \%$ of all cases), and drainage of CAF into the coronary sinus (CS) is found in $3-7 \%$ of all cases (see Table 1 ).

\section{Case report}

A 41-year-old woman with no significant past medical history presents with shortness of breath for the last 3 months. She had no constitutional symptoms except dyspnea and chest discomfort with moderate exertion which had affected her ability to carry out normal daily activities. She was hemodynamically stable and cardiovascular exam was negative for abnormal findings. Chest X-ray and 12 lead ECG were normal. Transesophageal echocardiography showed disturbed flow signal at the proximal CS, which appeared to be dilated (Fig. 1A). There was no regional wall dilation, motion abnormality, or valvular dysfunction. Cardiac catheterization confirmed a large CAF with origin at the distal

\footnotetext{
* Corresponding author.

E-mail address: lerodriguez26@yahoo.com (L.E. Rodriguez).

Peer review under responsibility of The Society of Cardiovascular Academy.
}

LCX converging with the proximal CS (Fig. 1B, white arrow). Due to the size and location of the fistula the patient was not considered for percutaneous approach by the interventional cardiology service, and an open approach on cardiopulmonary bypass was offered. Intraoperatively, pulmonary artery catheterization confirmed a physiologic left to right shunt with significant step up in mixed venous oxygenation (SvO2) to 92\%. Via median sternotomy and cardioplegic arrest, the fistula was identified (Fig. 1C) and ligated. The SvO2 returned to 70\% immediately upon ligation of the fistula. Post op day 1 she reported complete

Table 1

Incidence of coronary artery fistulas. ${ }^{1-4}$

\begin{tabular}{ll}
\hline Origin & Incidence \\
\hline Right coronary artery & $50 \%-60 \%$ \\
Left anterior descending artery & $25 \%-42 \%$ \\
Circumflex artery & $17-18.3 \%$ \\
Diagonal branch & $1.9 \%$ \\
Left main coronary artery or circumflex-marginal branch & $0.7 \%$ \\
Drainage & \\
Pulmonary artery & $15 \%-43 \%$ \\
Right ventricle & $14 \%-40 \%$ \\
Right atrium & $19 \%-26 \%$ \\
Left ventricle & $2 \%-19 \%$ \\
Coronary sinus & $3-7 \%$ \\
Left atrium & $5 \%-6 \%$ \\
Superior vena cava & $1 \%$ \\
\hline
\end{tabular}




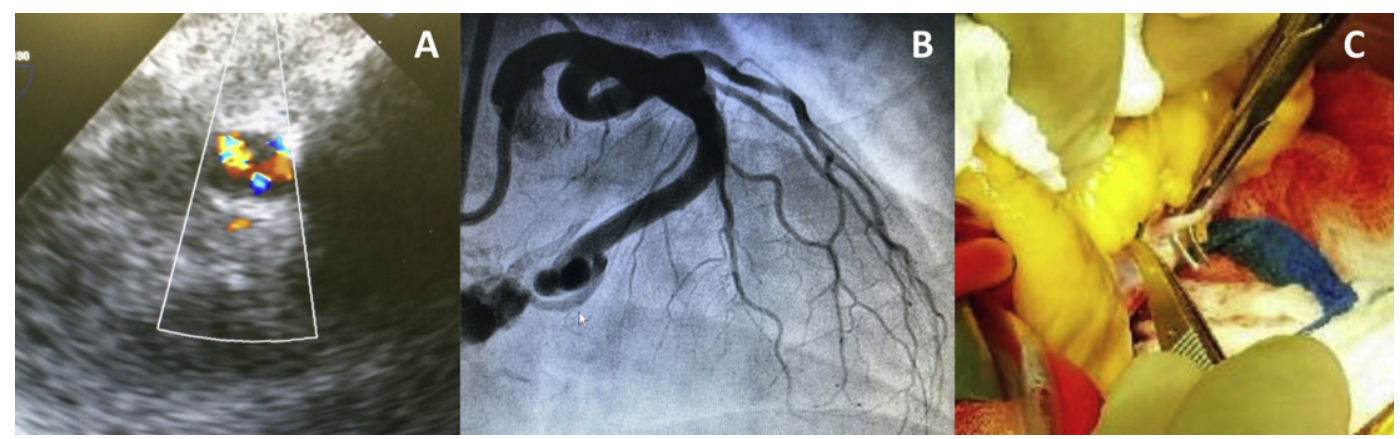

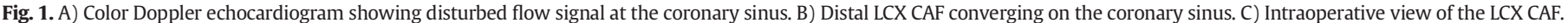

resolution of symptoms and was discharged 4 days later. At 6 month follow up, she was free of symptoms and back to her daily routine.

\section{Discussion}

In the setting of a symptomatic adult, urgent CAF exclusion (via open or endovascular approaches) constitutes optimal management. If left untreated the patient is at risk to develop highly morbid fistula related complications which include steal syndrome, dysrhythmias, endocarditis, and myocardial infarction. ${ }^{5}$ Moreover, CAFs that drain to the coronary sinus are particularly associated with progressive CHF, as we found in our patient. An open approach is indicated when the anatomy is not suitable (i.e. large fistula and/or aneurismal coronary artery) to undergo percutaneous closure and when there is additional pathology that can be corrected surgically. In our patient, surgical ligation was feasible because there was no transmural involvement and the large fistula was located at the distal end of the LCX. Surgical techniques for closure are associated with $16-22 \%$ risk of recurrence when compare to $10-50 \%$ with endovascular techniques. ${ }^{6}$ Another interesting finding in our patient was the usefulness of $\mathrm{SvO} 2$ to identify the intracardiac shunt. Normalization of the $\mathrm{SvO} 2$ upon ligation confirmed that the intervention had been successful from a physiologic stand point. In closing, large CAFs with high flow rates are often symptomatic and can lead to life- threatening complications. Prompt intervention is indicated and surgical approaches still offer excellent short and long term outcomes.

\section{Conflict of interest}

The authors declare no conflict of interest.

\section{References}

1. Hou Bin, Ma Wei-Guo, Zhang Jing Ming Du, Sun Han-Song Xu Jian-Ping Pan Shi-Wei. Surgical management of left circumflex coronary artery fistula: a 25-year single-center experience in 29 patients. Ann Thorac Surg 2014;97(2):530-536.

2. Mangukia Chirantan V. Coronary artery fistula. Ann Thorac Surg 2012;93(6): 2084-2092.

3. Raju Manjunath G, Goyal Sandeep K, Punnam Sujeeth R, Shah Dinesh O, Smith Georgie F, Abela George S. Coronary artery fistula: a case series with review of the literature. $J$ Cardiol 2009;53:467-472 (PubMed).

4. Vavuranakis M, Bush CA, Boudoulas H. Coronary artery fistulas in adults: incidence, angiographic characteristics, natural history. Catheter Cardiovasc Diagn 1995 Jun 1;35(2):116-120.

5. Liberthson RR, Sagar K, Berkoben JP, Weintraub RM, Levine FH. Congenital coronary arteriovenous fistula. Report of 13 patients, review of the literature and delineation of management. Circulation 1979 May 1;59(5):849-854.

6. Balanescu S, Sangiorgi G Castelvecchio S, Medda M, Inglese L Coronary artery fistulas: clinical consequences and methods of closure. A literature review. Ital Heart J 2001 Sep;2:669-676. 